\title{
Telemedicine and Perioperative Management of Obese Patients
}

\author{
Nora Terrasini ${ }^{1, *}$, Francesco Forfori ${ }^{1}$, Riccardo Taddei ${ }^{1}$, Erik Arbeid ${ }^{1}$, TM Hemmerling ${ }^{2}$ and \\ Francesco Giunta ${ }^{1}$
}

\author{
${ }^{I}$ Department of IV Anesthesia, Azienda Ospedaliero - Universitaria Pisana, Pisa, Italy \\ ${ }^{2}$ Department of Anesthesia, McGill University, Montreal, Canada
}

\begin{abstract}
Telemedicine is defined as the delivery of health care and the share of medical knowledge over distance using telecommunications systems. One of the main purposes of telemedicine is to improve accessibility to specialty consultation in remote areas and to reduce the costs of traditional health practices. Telemedicine is used in preoperative assessment and in anesthesia with positive perceptions by patients. Furthermore the possibility to realize transcontinental anesthesia, represents the pathway through which geographical barriers will be no longer limiting factors in high quality health care delivery.
\end{abstract}

Keywords: Anesthesia, health care, obesity, preoperative assessment, teleassessment, telemedicine.

\section{INTRODUCTION}

Telemedicine is defined as the delivery of health care and the share of medical knowledge over distance using telecommunications systems [1]. The World Health Organization gives a more extensive definition of what should be considered as telemedicine, describing it as "the delivery of healthcare services, where distance as a critical factor, by all healthcare professionals using information and communication technologies for exchange of valid information for diagnosis, treatment and prevention of disease and injuries, research and evaluation and for the continuing education of healthcare providers, all in the interests of advancing the health of individuals and their communities [2]. The telephone is the oldest system connecting patients and physicians, but nowadays the term telemedicine is usually applied to practices that implement video-conferencing software and equipment, such us the commonly used Skype (TM) or Windows Live Messenger [3].

One of the main purposes of telemedicine is improving accessibility to specialty consultation in remote areas. While the demand for medical care in rural areas is increasing, many patients cannot still access clinical consultation because of a lack of expertise on site. Besides, the need for telemedicine systems is increased by several issues, such as the unavailability of doctors and specialists, the poor communication and infrastructures, the inability of some patients to traveller and the scarcity of monetary resources. In particular, it has been observed that pediatric obesity is more prevalent in rural areas, where inaccessibility is the main obstacle to health care deliver [4, 5]. Another advantage of telemedicine is that it can be less expensive

*Address correspondence to this author at the Department of IV Anesthesia, Pisa, Italy; Tel: +39 050997608; Fax: +39 050997607;

E-mail: nora.terrasini@gmail.com than traditional practices. As a matter of fact, video consultation delivered to a rural clinic can replace an unaffordable travel to a tertiary healthcare centre, resulting in a reduction of the associated costs for patients. Besides, physicians may need to brainstorm about a particular case with colleagues with a fresher, more up-to-date, or more specific knowledge. In everyday life, patients at home could have remotely monitored several parameters, such as blood pressure, heart-beat, weight, blood glucose; which can be sent in real-time to the health care provider via telecommunication devices. Moreover, telecommunications applied to medicine open up a plethora of new possibilities, from continuing education to training new personnel.

\section{THE EARLIEST ATTEMPTS OF TELEMEDICINE}

Some early attempts to make use of telemedicine have been explored since the 1970's. A two-way telemedicine system was experimented for consultation in anesthesia [6]. The aim of the system was to connect an operating room at the Cleveland Veteran's Administration Hospital with a consulting room (an anesthesia suite) at the University Hospitals, Case Westem Reserve University School of Medicine (UHC). The telemedicine system successfully provided voice, vision, and electronic display links between the two stations. The consultant could view the patient and the anesthetizing area through a remotely controlled camera. This experiment was a milestone for telemedicine, in fact, as the authors stated, real-time TV images were of dramatic relevance in anesthesia consultation and could not be substituted by electrocardiogram or other data transmitted via telephone.

Another interesting example of telemedicine was experimented at the Massachusetts General Hospital; physicians provided primary medical care to 1000 patients 2.7 miles away at the Logan International Airport Medical Station using a two-way closed circuit television [7]. The 
medical station at the airport was established to provide occupational health services to airport employees and to give emergency care and medical direction also to travellers. During the experiment, nurses were present at the medical station for $24 \mathrm{~h}$; with the possibility to ask for physician's consultation on demand via telephone. A visual communication system was also implemented to reproduce a quasi-normal clinical setting (patient-doctor) with the aid of a visual communication transmission.

\section{APPLICATIONS OF TELEMEDICINE IN PREOPERATIVE ASSESSMENT}

Inadequate preoperative patient evaluation can result in cancelling a scheduled procedure on the day of surgery; that is never ideal. Preadmission anesthesia consultations via telemedicine system can successfully account for that; in particular, with obese patients who usually present several complications [8].

The University Health Network in Toronto conducted a pilot study in partnership with the Northern Ontario Remote Telecommunication Health Network. The aim of the project was to provide telemedicine clinical consultations to residents of central and northern Ontario, Canada [9]. The authors reported on pre-operative assessments conducted on a group of 10 patients in 2003. An anesthesiologist was present at the physician site, while a nurse assisted the patient at the remote site during anesthesia consultation. When connected to the remote site, the anesthesiologist could visualize, hear, and auscultate the patient using a digital stethoscope system, therefore he was able to collect the patient's history and then to perform the examination of the airways, respiratory and cardiovascular system. As a result, all the patients and the anesthesiologists were satisfied with telemedicine anesthesia consultation.

A similar study was conducted between 1996 and 1997 by Rollert and colleagues [10]. Forty-three patients were visited with telemedicine consultation for preoperative assessment. They defined tele-consultation's efficiency as the ability to conduct surgery with general anesthesia on the day of the first clinic appointment, without the need of further preoperative testing in direct contact with the patient. They demonstrated that triage was correctly performed on $100 \%$ of the patients while only $4 \%$ ( 2 patients out of 43 ) had to undergo extra evaluation at the hospital after telemedicine pre-operative assessment. One of the 2 patients, who needed further on site clinical exams, was a morbid obese 21-year-old man with inadequately controlled hypertension, and he was also not regularly followed-up by a general physician.

The preoperative telemedicine evaluation resulted very feasible, accurate, and efficient, but it is also important to consider the patient's acceptance to this new technology. Boedeker and colleagues investigated the perception of telemedicine preoperative assessment [11]. Tele preoperative evaluation was proposed to patients, instead of travelling for routine anesthesia assessment. Immediately after the teleassessment, patients were asked to fill a validated questionnaire, designed to measure their feelings about the experience with telemedicine, especially for what concern technical quality, perceived efficacy, affective patient experience and patient preference. The study reported that patients accepted remote preoperative assessment services and showed positive perceptions in all the examined domains.

\section{REMOTE PREOPERATIVE ASSESSMENT IN OBESE PATIENTS}

Although, difficult intubation rate is higher in obese than in lean patients $[12,13]$, some cohorts advocate that this issue is still controversial, since evidences of this phenomenon are not clear [14]. In patients with morbid obesity standard predictors of difficult intubation are not satisfactory. In addition to the Mallampati score (a method used to predict difficult intubation) [15], the neck circumference at the level of the thyroid cartilage is also very important. The co-presence of high Mallampati score and large neck circumference is a good predictor of difficult intubation. Morbidly obese patients (BMI $>40 \mathrm{~kg} / \mathrm{m}^{2}$ ), with Mallampati class III and IV, and a neck circumference equal or larger than $43 \mathrm{~cm}$, are more prone to difficult intubation $[16,17]$. If accompanied with normal parameters, BMI per se cannot be considered a good predictor of difficult intubation $[18,19]$, but a BMI equal or above $26 \mathrm{Kg} / \mathrm{m}^{2}$ can lead to complication for what concerns ventilation through a bag-mask [20, 21]. In this regard, an original framework (including both software and procedures) has been presented as a pilot study at the American Society of Anesthesiologists annual meeting 2012 [22]. Dr. Hemmerling and his team developed a system, called Pre-Op Cockpit that is useful to remotely assess patient's airways, and to collect patient's history. The system consists of 2 stations: one at the physician's end (PC-1), the other at the patient's end (PC-2). PC-1 runs the Pre-Op Cockpit and communicates with PC-2 via Skype (Skype Inc. Luxembourg City, Luxembourg). The software is able to automatically measure, using webcam snapshots, the thyro-mental distance, the mouth opening, and above all, the neck circumference. During the video-call it is also possible to assess Mallampati and Mallampati with phonation. Medical history is collected by filling a built-in predefined yes/no pattern questionnaire of diseases. The PreOp Cockpit also automatically outputs BMI based on weight and height reported by patients. The pilot study was conducted on the authors themselves and showed good agreement with standard preoperative assessment. The same team is currently conducting a study to evaluate the real potential and accuracy of the Pre-Op Cockpit on obese patients undergoing bariatric surgery at Nuovo S.Chiara Hospital, AOUP, University of Pisa, Pisa, Italy. Preliminary results are encouraging. In the latter experiment described, researchers implemented common and broad spread communication technologies; consequently is reasonable to imagine that remote preoperative assessment will be feasible at patients' home in the future.

\section{APPLICATIONS OF TELEMEDICINE IN ANESTHESIA}

Telemedicine is not only used for preoperative assessment but also for remote anesthetic monitoring. As reported by Cone and colleagues, "A 35 year-old woman was admitted for cholecystectomy under general anesthesia in remote sector of Ecuador. Using teleconferencing 
connection $[\ldots]$ the managing anesthesiologist in Ecuador and the consulting anesthesiologist at Virginia Commonwealth University (VCU) shared anesthesia plan and airway evaluation" [23]. The patient's airway was classified as difficult to intubate. Parameters such as electrocardiogram (ECG) waveform, oxygen saturation, blood pressure, breath sound, voice contact, and video images of the anesthesia site were recorded in Ecuador and transmitted in real-time to VCU. During the first attempt to intubate the patient, a few premature ventricular beats were recognized thanks to the ECG at VCU; shortly thereafter the arrhythmia got worse and oxygen saturation decreased. This trend was noted by the consulting anesthesiologist at VCU, and at this time both teams agreed that conscious nasal intubation was needed, hence, they decided to wake up the patient.

The importance of telemedicine in anesthesia is also shown by two case studies of liver pediatric transplant. These transplants were performed at the Narayana Hrudayalaya Institute of Medical Sciences in Bangalore, India, with both the pre and intra operative consultation provided by anesthesiologists at the Children's Hospital of Philadelphia [24].

\section{TRANSCONTINENTAL ANESTHESIA}

The first world remote anesthesia was performed on August 30, 2010 by Dr. Hemmerling and his team (MGH, Montreal, QC, Canada) in collaboration with the IV Anesthesia Department directed by Dr. Giunta (Cisanello Hospital, Pisa, Italy) [25]. Via standard internet connection and remote desktop control software, anesthesiologists from Montreal were connected to the operating room in Pisa. Four video cameras were strategically placed to monitor every aspect of patient care in Pisa, audiovisual data were sent via streaming in real-time to the physician in Montreal. Three of the cameras were used to monitor patient's breathing rate and other ventilation parameters, vital signs (ECG, heart rate, and oxygen saturation) and live audiovisual of the surgery; while the fourth was used for special purposes. Differently from the studies previously mentioned, where there remote monitoring was only one, this experiment introduced an innovative key element. In this case, the total intravenous anesthesia was remotely controlled trough an automated system (Anesthesia Cockpit), which is a closed loop system that controls the effect of the drugs by monitoring appropriate parameters, such as heart rate, blood pressure, and level of consciousness as well as the regulation of anesthetic drugs infusion [26, 27].

Automated anesthesia delivering systems can be also used to deliver proficiently anesthesia to obese patients, but in this case several precautions are necessary. Anesthesia drug dosages in obese patients are based on 3 different body weight calculations: the total body weight (TBW); the lean body weight (LBW), the ideal body weight (IBW), which is the ideal weight according to age, height, sex, and bone density. In obese patients, drug dosages of hypnotic agents according to the LBW is shown to be the most appropriate (including propofol, induction dose $1-2.5 \mathrm{mg} / \mathrm{kg}$ ) [28]. The most commonly used opioids during induction are fentanyl $(2-6 \mu \mathrm{g} / \mathrm{kg})$ and remifentanil $(0.1-1.0 \mu \mathrm{g} / \mathrm{kg} / \mathrm{min})$, which are properly dosed using LBW [28]. The action of muscle relaxant drugs, such as rocuronium $(0.6 \mathrm{mg} / \mathrm{kg})$ and cisatracurium $(0.15 \mathrm{mg} / \mathrm{kg})$, is prolonged in obese patients when their dosage is based on the TBW. Therefore, dosages based on IBW are preferred [28].

Clinically significant obesity (body mass index BMI $\geq 30$ $\mathrm{kg} / \mathrm{m}^{2}$ ) incidence over industrialized population is growing at an unprecedented rate, since the 1970s. The prevalence in the United States in 2008 was about 32\% [29]. Consequently, an increasing number of obese patients regularly undergoes anesthesia, which forces anesthesiologist to account for potential complications, especially in regard of airway management [20].

\section{CONCLUSION}

The studies hereby presented show the progress, the efficacy and the advantages of telemedicine for both anesthesia delivery and preoperative assessment. Experiments like the transcontinental anesthesia represent the pathway through which geographical barriers will be no longer limiting factors in high quality health care delivery. Telemedicine in anesthesia already reached good achievements not exclusively for ASA I-II patients, but also for ASA III-IV patients such as morbidly obese subjects.

\section{CONFLICT OF INTEREST}

The authors confirm that this article content has no conflicts of interest.

\section{ACKNOWLEDGEMENTS}

The work has been partially supported by an unrestricted grant of the Italian Ministry of Foreign Affairs under the program "Programmi di alta rilevanza scientifica e tecnologica Italia-Messico".

\section{ABBREVIATIONS}

$\begin{array}{lll}\mathrm{ASA} & =\text { America Society of Anesthesiologists } \\ \mathrm{ECG} & =\text { electrocardiogram } \\ \mathrm{IBW} & = & \text { the ideal body weight } \\ \mathrm{LBW} & = & \text { the lean body weight } \\ \mathrm{TBW} & = & \text { total body weight }\end{array}$

\section{REFERENCES}

[1] Strode SW, Gustke S, Allen A. Technical and clinical progress in telemedicine. JAMA 1999; 281(12): 1066-8.

[2] Chatrath V, Attri JP, Chatrath R. Telemedicine and anaesthesia. Indian J Anaesth 2010; 54(3): 199-204.

[3] Galvez JA, Rehman MA. Telemedicine in anesthesia: an update. Curr Opin Anaesthesiol 2011; 24(4): 459-62.

[4] Cohen GM, Irby MB, Boles K, et al. Telemedicine and Pediatric Obesity Treatment: Review of the literature and lessons learned. Clin Obes 2012; 2(3-4):103-11.

[5] Irby MB, Boles KA, Jordan C, et al. TeleFIT: adapting a multidisciplinary, tertiary-care pediatric obesity clinic to rural populations. Telemed J E Health 2012; 18(3): 247-9.

[6] Gravenstein JS, Berzina-Moettus L, Regan A, et al. Laser mediated telemedicine in anesthesia. Anesth Analg 1974; 53(4): 605-9.

[7] Murphy RL, Jr., Bird KT. Telediagnosis: a new community health resource. Observations on the feasibility of telediagnosis based on 1000 patient transactions. Am J Public Health 1974; 64(2): 113-9. 
[8] Taddei M, Terrasini N, Zaouter C, et al. Airway Management in Bariatric Surgery: A Challenge for Anesthesiologists Bariater Times 2012; 9(2): 28.

[9] Wong DT, Kamming D, Salenieks ME, et al. Preadmission anesthesia consultation using telemedicine technology: a pilot study. Anesthesiology 2004; 100(6): 1605-7.

[10] Rollert MK, Strauss RA, Abubaker AO, et al. Telemedicine consultations in oral and maxillofacial surgery. J Oral Maxillofac Surg 1999; 57(2): 136-8.

[11] Boedeker BH, Murray WB, Berg BW. Patient perceptions of preoperative anaesthesia assessment at a distance. Journal of Telemed Telecare 2007; 13(suppl 3): 22-4.

[12] Juvin P, Lavaut E, Dupont $\mathrm{H}$, et al. Difficult tracheal intubation is more common in obese than in lean patients. Anesth Analg 2003; 97(2): 595-600, table of contents.

[13] Shiga T, Wajima Z, Inoue T, et al. Predicting difficult intubation in apparently normal patients: a meta-analysis of bedside screening test performance. Anesthesiology 2005; 103(2): 429-37.

[14] Collins JS, Lemmens HJM, Brodsky JB. Obesity and Difficult Intubation: Where Is the Evidence? Anesthesiology 2006; 104(3): 617.

[15] Samsoon GL, Young JR. Difficult tracheal intubation: a retrospective study. Anaesthesia 1987; 42(5): 487-90.

[16] Kristensen MS. Airway management and morbid obesity. European J Anaesthesiol 2010; 27(11): 923-7.

[17] Brodsky JB, Lemmens HJ, Brock-Utne JG, et al. Morbid obesity and tracheal intubation. Anesth Analg 2002; 94(3): 732-6; table of contents.

[18] Lundstrom LH, Moller AM, Rosenstock C, et al. High body mass index is a weak predictor for difficult and failed tracheal intubation: a cohort study of 91,332 consecutive patients scheduled for direct laryngoscopy registered in the Danish Anesthesia Database. Anesthesiology 2009; 110(2): 266-74.
[19] Ezri T, Medalion B, Weisenberg M, et al. Increased body mass index per se is not a predictor of difficult laryngoscopy. Can J Anaesth 2003; 50(2): 179-83.

[20] El Solh AA. Airway management in the obese patient. Clin Chest Med 2009; 30(3): 555-68.

[21] Langeron O, Masso E, Huraux C, et al. Prediction of difficult mask ventilation. Anesthesiology 2000; 92(5): 1229-36.

[22] Hemmerling TM, Terrasini NPM, Eds. Remote Airway Assessment. Anesthesiology, ASA meeting; 2012; Washington, D.C. 2012

[23] Cone SW, Gehr L, Hummel R, et al. Case report of remote anesthetic monitoring using telemedicine. Anesth Analg 2004; 98(2): 386-8, table of contents.

[24] Fiadjoe J, Gurnaney H, Muralidhar K, et al. Telemedicine consultation and monitoring for pediatric liver transplant. Anesth Analg 2009; 108(4): 1212-4.

[25] Hemmerling TM, Arbeid E, Tang L, et al. Transcontinental Anesthesia in Abstracts of the 2011 Annual Meeting of the Society for Technology in Anesthesia (STA). January 12-15, 2011. Las Vegas, Nevada, USA. Anesth Analg 2011; 113(2 Suppl):42.

[26] Hemmerling TM, Samer Charabati MS, McSleepy TM. A completely Automatic Anesthesia delivery system. Annual Meeting of the American Society Anesthesiologists. October 17 - 21, 2009; New Orleans, Louisiana, USA 2009.

[27] Hemmerling TM, Zaouter C, Tang L, et al. McSleepy - A novel completely automatic anesthesia delivery system: performance evaluation in comparison to manual control in Abstracts of 2010 CAS Meeting. Can J Anesth 2010; 57: 116.

[28] Ingrande J, Lemmens HJ. Dose adjustment of anaesthetics in the morbidly obese. Br J Anaesth 2010; 105 (Suppl 1): i16-23.

[29] Wang YC, McPherson K, Marsh T, et al. Health and economic burden of the projected obesity trends in the USA and the UK. Lancet 2011; 378(9793): 815-25.

Received: January 17, 2013

(C) Terrasini et al.; Licensee Bentham Open.

This is an open access article licensed under the terms of the Creative Commons Attribution Non-Commercial License (http://creativecommons.org/licenses/by-nc/3.0/) which permits unrestricted, non-commercial use, distribution and reproduction in any medium, provided the work is properly cited. 